\title{
Is Blood Quantum Back In Circulation?
}

Identity is one of those elusive concepts that, when hearing the word 'identity' uttered, we all nod in understanding. But when we give it just a little thought we soon realise it is as hard to capture as a fruit fly in a glass of sauvignon blanc - just when we think we've got it, and we're poised to flick it out of the glass and hold it up for closer inspection and analysis, it slips away and we're back to square one. And so the process starts again and is repeated until we are successful in capturing the fly. Much like the fruit fly metaphor, many scholars have set out to pin down this notion of identity, and the copious amount of research in this area is evidence of our determination and need to grasp it. Some general consensus has emerged from the struggle, and it is widely accepted that culture and ethnicity play key roles in issues of identity. An analysis of the identity discourse as it relates to culture and ethnicity reveals a move away from binary and clinical notions of identity that spawned ideas such as blood quantum, to a place where social acceptance and belonging are at the heart of identity. Essentially, one identifies with a group, is accepted by that group, and with that acceptance and belonging comes certain rights (or not) and responsibilities.

Recently, we published an article (https://www.tekaharoa.com/index.php/tekaharoa/article/vi ew/207/189) where we posed the question: Is te reo Māori (the Māori language) the new blood quantum? This question was

Sonja Macfarlane (Ngāti Waewae, Ngāi Tahu) is an Associate Professor in the College of Education, Health and Human Development at the University of Canterbury, New Zealand.

Melissa Derby (Ngāti Ranginui) is a Ph.D candidate in the College of Education, Health and Human Development at the University of Canterbury, New Zealand. 
borne out of observations in professional and social settings, whereby one's ability to speak te reo Māori- or their 'reo quantum' (with the pervading question being "How high is your $\mathrm{RQ}$ ?) - determines 'how Māori' (or not) that person is perceived to be. In essence, our key message in the article was one of advocacy for an inclusive approach, where, as a result of the colonial need to put an end to te reo Māori, we recognise that we each have our own unique relationship with te reo Māori one that is heavily influenced by our individual experiences and desires. Out the outset of the article, we noted - with jubilation - that the archaic notion of blood quantum, whereby one's identity is determined by applying a mathematical formula to our genealogy and DNA in order to decide if we belong to a certain ethnic group or not, is no longer accepted practice in Aotearoa New Zealand. Or is it? Is the idea of blood quantum underpinning some areas of modern day thinking?

Recent public debate suggests this may be the case in some instances, and that blood quantum as a means of determining, for example, rights to initiate or participate in a conversation, is in fact alive and well - although like so many archaic ideas and practices, it has re-emerged in the $21^{\text {st }}$ century in a less overt manner. In the realm of debate that focuses on issues of equity, human rights, decolonisation, and advancement for Māori (among other things) is there room for Pākehā voices? Or is the right to offer comment on such issues reserved only for Māori? Increasingly, we see comments on in the public sphere suggesting that there is no place for Pākehā in these conversations - unless their views serve to affirm a romanticised school of thought. A recent example emerged on social media following the publication of a book that critiqued strategies aimed at revitalising te reo Māori. Rather than focusing on the intent of the author's kōrero, what emerged were personal attacks on the author, a number of which questioned the author's right to offer comment on anything associated with te reo Māori because the author is not Māori.

Comments in this vain honed in on ethnicity in particular or blood quantum? - and seemed to suggest that it is the defining factor in the right to pass comment in this space. 
Interestingly, comments made by Pākehā who were critical of the book and the author seemed to be accepted by Māori as having credibility.

And so we began to ponder the following. Do we let Pākehā speak on issues concerning Māori only if we like or agree with what is being said? In this instance, it seems we would see Pākehā individuals as allies and supporters of Māori causes; their ethnicity is not an issue and they are welcome to join the conversation - or at the very least they are not banned from it. But what if we don't like what Pākehā are saying? It seems in that instance that their ethnicity comes very much to the fore; they are suddenly thrown into the category of 'Yet Another Racist Pākehā', and we insist that because of their ethnicity (full-blooded Pākehā) they are not permitted to participate or offer comment. Ultimately, is Pākehā commentary on things Māori always unwelcome, always unhelpful, always inappropriate - and always racist?

One of the strengths of our tupuna (ancestors) was their ability to practise deep listening, and to engage in raw and constructive debate, which can be encapsulated in the whakatauki (proverb): Ko te kai a te rangatira he kōrero (discussion is the food of chiefs). We are not advocating for undue pessimism or superficial optimism, but rather encourage the adoption of a realistic position where we are able to promote robust and respectful dialogue with our Treaty partner that is solutions-focused and aspirational. We also need to be mindful not to venture down the perilous pathway of censoring people based on their ethnicity but rather ensure we are able to hear a range of views, and discuss the merit of the view, not the quantum of blood. 